\title{
Comparative use of oyster shell and limestone as sources of calcium in the diet of
} laying chickens

${ }^{1}$ Mako, A. A., ${ }^{* 2}$ Mosuro, A. O., ${ }^{2}$ Adedeji, B. S., ${ }^{2}$ Jemiseye, F. O. and ${ }^{2}$ Abokede, T. ${ }^{1}$ Department of Agricultural Science, Tai Solarin University of Education, Ijebu-Ode. Ogun State. Nigeria

${ }^{2}$ Agricultural Biochemistry and Nutrition Unit, Department of Animal Science, University of Ibadan, Nigeria

Abstract ${ }^{*}$ Corresponding author: ronke.mosuro@outlook.com; 09038159961

Egg producers primarily use oyster shell or limestone as supplemental sources of dietary calcium. This study was conducted to investigate the efficiencies of limestone (CaCo$)$ and oyster shell as calcium sources in the diets of laying hens. Ninety, 58 weeks old Golden Comet Hubbard laying birds were randomly allotted to three treatments of three replicates. Each replicate had 10 birds per replicate. Three different rations were formulated for the study. To include Diet 1 as the control, a diet with bone meal (46\%) and oyster shell (54\%). Diet 2 had oyster shell and bone meal supplying $82 \%$ and $18 \%$ of the dietary calcium while Diet 3 had $82 \%$ and $18 \%$ of the dietary calcium supplied by limestone and bone meal respectively. Feed and water were provided ad-libitum. The parameters measured include: Feed intake (g/d); Hen day production (\%); Efficiency of feed utilization ( $\mathrm{kg})$; Egg and shell weight (g); Bone weight (g); Ash content of bone (\%) and Calcium content of bone (\%). The study lasted eight weeks. Results revealed that birds on Diet1 had the highest value for feed intake $(0.11 \mathrm{~g} / \mathrm{d})$ that differed significantly $(P<0.05)$ from the value $(0.10 \mathrm{~g} / d)$ obtained for Diet 2 and 3 Hen day production for birds on Diet 2 (57.04) and Diet 3 (56.30) were similar, but differed significantly $(P<0.05)$ from birds on Diet 1 (65.44). Efficiency of feed utilization (EFU $\mathrm{kg})$ was not significantly affected by the dietary treatments as birds on Diet 1 had the lowest EFU value (1.80) while birds on Diet 2 had the highest EFU value (2.05). A higher percent of eggs within 50-59g were laid by birds on Diet 3, while eggs of $60 \mathrm{~g}$ and above were laid by birds on Diet 1 (62 g), significant $(p<0.05)$ variations occurred among treatment means for these egg grade. Egg shell percent was not significant, same trend was observed for bone weight. The effect of dietary treatment on the ash content of bones were similar for birds on Diet 2 and 3 , except for bone humerus, however, significant $(p<0.05)$ variation occurred between birds on diets 1 and other two Diets. Calcium contents of the different bones were differed significantly $(p<0.05)$ with birds on diet 3 recording the highest values for all bone investigated. It can be concluded from this study that Limestone can replace oyster shell as a source of calcium in the diet of laying hens without deleterious effect.

\section{Keywords: Bone mineral, calcium, limestone, oyster shell, laying chickens}

\section{Introduction}

Laying hens have high demand for calcium, especially during peak egg production when calcium output is at its greatest. Calcium is essential for egg formation as the medullary bone is a woven bone that acts as a labile source of calcium for eggshell formation (Whitehead, 2004).
Leeson and Summers (2005) stated that deficiency of calcium resulted in decreased egg production and mobilization of calcium from bone. The nutritional role of $\mathrm{Ca}$ is closely linked to that of phosphorus as its release from bones is along with phosphorus (Arajuo et al., 2005). Calcium requirement of the laying hens is 3-4.5 


\section{Comparative use of oyster shell and limestone as sources of calcium in the diet of laying chickens}

$\mathrm{g} /$ hen/day and phosphorus/non-phytate phosphorus requirement is $250 \mathrm{mg} / \mathrm{hen} /$ day (NRC, 1994). Calcium nutrition also plays a significant role in bone quality of the laying hen as poor bone quality in laying hens can lead to broken or weak bones, osteoporosis, economic losses and difficulties at processing plants that as a result of bone fragments in meat products (Whitehead and Fleming, 2000; Webster, 2004; Julian, 2005). Livestock producers primarily use either oyster shell or limestone as their major supplemental sources of dietary calcium. Oyster shell for more than 100years (Roland and Bryant, 1999) has become a proven source of calcium to laying hens for maintaining good quality egg shells. Roland (1986) in his review of studies comparing limestone and oyster shell, observed that half of the studies conducted in his review concluded that oyster shell resulted in better egg shell quality, whereas others reported that egg shell quality was not affected. SanderBlades et al. (2009) however, posited that the improved egg shell quality from feeding oystershell may be more of calcium particle size, rather than the calcium source per se. Scott et al. (1971) speculated that the larger particles stay longer in the upper digestive tract (crop and gizzard) than the ground calcium sources thus making calcium available to the hen for a longer period of time. Roland (1986) concluded that large particle size had no effect on shell quality when calcium levels in the diet are adequate. Large particle calcium has been shown to have a positive effect on layer bone quality (Guinotte and Nys, 1991; Rennie et al., 1997; Fleming et al., 1998). Since either oyster shell or limestone can provide approximately $38 \% \mathrm{Ca}$, limestone should be able to efficiently replace oyster shell. Also, limestone which is available in vast quantities, costs considerably less than the less abundant oyster shell in Nigeria. This study was carried out to compare the efficiency of limestone and oyster shell as sources of calcium in diets of laying hens in the humid tropics.

\section{Materials and method Experimental Location}

The experiment was carried out at the poultry unit of the Teaching and Research Farm, University of Ibadan, Nigeria. It is situated in the derived Savanna vegetation belt on longitude $7^{0} 27.05$ North and latitude $3^{0} 53.74$ of the Greenwich Meridian East at an altitude $200 \mathrm{~m}$ above sea level. Temperature range and the average relative humidity of the location were between 23$25^{\circ} \mathrm{C}$ and $60 \%$ respectively. The duration of the study was eight weeks.

\section{Experimental birds and management}

Ninety, 58 weeks old Golden Comet Hubbard laying birds were procured for the study. They were randomly allotted to 3 treatments of 3 replicates and each replicate had 10 birds per replicate. Feed and water were provided ad-libitum while routine medical, vaccination and husbandry practices were observed.

\section{Experimental diets}

Three different rations were formulated for the study. Diet 1 was the control a diet with bone meal (46\%) and oyster shell (54\%) as source of calcium. Diet 2 was similar to diet 1 but had oyster shell and bone meal supplying $82 \%$ and $18 \%$ of the dietary calcium while diet 3 had $82 \%$ and $18 \%$ of the dietary calcium supplied by $\mathrm{CaCo}_{3}$ and bone meal respectively. The diet composition is shown in Table 1.

Feed intake was obtained from total amount of feed offered less feed refusal per week. Hen day production was calculated from daily egg production. Egg weights/grade was obtained by collection of eggs on daily basis and placing into categories of $60 \mathrm{~g}$ and 
Mako, Mosuro, Adedeji, Jemiseye and Abokede

Table 1: Composition of experimental Diets (\%) of laying chickens fed different sources of calcium

\begin{tabular}{llcl}
\hline & \multicolumn{3}{c}{ Experimental Diets } \\
\cline { 2 - 4 } Ingredients & Diet 1 & Diet 2 & Diet 3 \\
\hline Maize & 58.25 & 58.95 & 58.10 \\
Soya bean & 15.00 & 15.00 & 15.00 \\
Brewers dry grain & 10.00 & 10.00 & 10.00 \\
Fish meal & 2.00 & 2.00 & 2.00 \\
PKC & 5.00 & 5.00 & 5.00 \\
Bone meal & 5.00 & 2.00 & 2.00 \\
Oyster shell & 4.50 & 6.80 & 0.00 \\
Limestone & 0.00 & 0.00 & 7.65 \\
Vitamin-mineral premix & 0.25 & 0.25 & 0.25 \\
Total & $\mathbf{1 0 0}$ & $\mathbf{1 0 0}$ & $\mathbf{1 0 0}$ \\
Calculated Nutrients & & & \\
Crude protein & 15.64 & 15.63 & 15.70 \\
Calcium from oyster shell & 54.11 & 81.70 & 0.00 \\
Calcium from limestone & 0.00 & 0.00 & 81.70 \\
Calcium from bone meal & 45.89 & 18.30 & 18.30 \\
\hline
\end{tabular}

Table 2: Performance of laying chickens fed different calcium sources

\begin{tabular}{lllll}
\hline Parameters & Diet 1 & Diet 2 & Diet 3 & SEM \\
\hline Feed intake $(\mathrm{g} / \mathrm{d})$ & $0.11^{\mathrm{a}}$ & $0.10^{\mathrm{b}}$ & $0.10^{\mathrm{b}}$ & 0.001 \\
Hen day production $(\%)$ & $65.44^{\mathrm{a}}$ & $57.04^{\mathrm{b}}$ & $56.30^{\mathrm{b}}$ & 0.240 \\
Efficiency of feed utilization $(\mathrm{kg})$ & 1.80 & 2.05 & 1.81 & 0.06 \\
\hline
\end{tabular}

${ }^{\mathrm{ab}}$ means with different superscript on the same row differed significantly $(\mathrm{P}<0.05)$

above, 50-59g, 50g and below. Egg shell weight was obtained from the weight of the dried shell after the content had been removed and weighed using a sensitive scale, while percent egg shell weight is calculated using this formula:

Weight of shell $\times 100$

Weight of egg

\section{Bone analysis}

Two birds per replicate were randomly selected and slaughtered at the end of the experiment. Bones (ulna, tibia, femur, radius, humerus and metatarsal) from the right side of each bird were removed, scalded, de-fleshed and oven dried at $90^{\circ} \mathrm{C}$ for $48 \mathrm{hrs}$. The dry bones were thereafter ashed for calcium assay according to AOAC (2000).

\section{Results and discussion}

Performance characteristics of birds fed ground limestone and oyster shell as sources of calcium is shown in Table 2. Feed intake of birds on diets 2 and 3 were similar $(\mathrm{P}>0.05)$ but differed from birds on Diet 1 that had significantly higher $(\mathrm{P}<0.05)$ feed intake. The significant difference $(\mathrm{P}<0.05)$ observed in feed intake is corroborated by the report of Yusuf (2014) that feed intake is affected by dietary calcium sources. However this finding is at variance with the report of Ahmed et al. (2013) who reported a lower feed intake by 24 weeks old Bovan pullets on oyster shell compared to those on limestone treatment. From this result it could be inferred that dietary calcium source has no effect on feed intake. Hen day production (57.04 and $56.30 \%$ ) for birds on Diets 2 and 3 respectively were similar, but differed significantly $(\mathrm{P}<0.05)$ from birds on Diet 1 $(65.44 \%)$. These results support previous research elsewhere, that found egg production not to differ among hens fed 
limestone or oyster shell (Guinotte and Nys, 1991; Grizzle et al., 1992; Saunder-Blades et al., 2009) but contradicts Ahmed et al. (2013) that decrease in lay rate percent by pullets fed oyster shell compared to those fed limestone as sources of calcium. The similar result of hen day production from different calcium sources in this study might be due to the fact that, satisfactory amount of calcium were available from the calcium sources to support and sustain similar egg production. EFU was not significantly affected $(\mathrm{P}>0.05)$ by the dietary treatments as birds on Diet1 had the lowest value $(1.80 \mathrm{~kg})$ while those on Diet 2 had the highest value $(2.05 \mathrm{~kg})$. This observation was in line with studies (Keshavarz et al.1993; Scheideler, 1998 and Saunder-Blades et al., 2009) that reported no significant differences in the performance of birds on different calcium sources. Table 3 shows the effect of the dietary limestone. Fewer eggs within the range $40-49 \mathrm{~g}$ were found, as the experiment progressed, less and less eggs within this grade were laid, thus enough of eggs within this range were not available for analysis.

Table 3: Egg and shell weights (g) of laying chickens fed different calcium sources

\begin{tabular}{lllll}
\hline & Diet 1 & Diet 2 & Diet 3 & SEM \\
\hline Egg grade & & & & \\
$40-49 \mathrm{~g}$ & 3.80 & 1.52 & 2.52 & \\
$50-59 \mathrm{~g}$ & $41.27^{\mathrm{c}}$ & $50.28^{\mathrm{b}}$ & $59.70^{\mathrm{a}}$ & 0.22 \\
60>above & $62.00^{\mathrm{a}}$ & $48.89^{\mathrm{b}}$ & $38.41^{\mathrm{c}}$ & 0.45 \\
Egg shell weight & & & & \\
$40-49 \mathrm{~g}$ & 9.20 & 8.86 & 8.55 & \\
$50-59 \mathrm{~g}$ & 8.79 & 8.58 & 8.80 & 0.31 \\
$60>$ above & 8.53 & 8.39 & 8.63 & 0.23 \\
\hline
\end{tabular}

${ }^{a b c}$ means with different superscript on the same row differred significantly $(\mathrm{P}<0.05)$

Egg weight differed significantly $(\mathrm{P}<0.0 .05)$ among the treatment means. A higher percent egg weight $(59.70 \mathrm{~g})$ of eggs within $50-59 \mathrm{~g}$ were laid by birds on Diet 3 while eggs of $60 \mathrm{~g}$ and above were laid by birds on Diet 3 (62.00), although no particular trend was observed for egg weight. The egg shell weight did not vary significantly, however, the highest egg shell weight $(8.80$ and $8.63 \mathrm{~g}$ ) was obtained from birds on Diet 3 for egg grade between 50$59 \mathrm{~g}$ and $60 \mathrm{~g}$ and above respectively, while birds on Diet 3 recorded the lowest egg shell value ( 8.58 and $8.39 \mathrm{~g}$ ) for egg grade between $50-59 \mathrm{~g}$ and $60 \mathrm{~g}$ and above respectively. This result was in agreement with the findings elsewhere (SaunderBlades et al., 2009)

Table 4: Bone weight (g) of laying chickens fed different calcium sources

\begin{tabular}{lllll}
\hline Bone types & Diet 1 & Diet 2 & Diet 3 & SEM \\
\hline Tibia & 2.23 & 2.20 & 2.38 & 0.12 \\
Femur & 1.75 & 1.66 & 1.61 & 0.12 \\
Metatarsal & 0.89 & 1.05 & 1.05 & 0.17 \\
Humerus & 0.78 & 0.79 & 0.75 & 0.05 \\
Radius & 0.58 & 0.55 & 0.62 & 0.04 \\
Ulna & 0.20 & 0.19 & 0.20 & 0.02 \\
\hline
\end{tabular}

Percentage bone weight of laying birds fed oyster shell and limestone is shown in Table 4. There were no significant differences
$(\mathrm{P}>0.05)$ in the weight of the different bones measured. However, tibia and radius weights of birds on Diet 3 were relatively 
higher than those obtained from birds on Diets 1 and 2. Contrary results found by some authors (Guinotte and Nys 1991; Rennie et al. 1997; Fleming et al. 1998) all pointed to increased bone quality though this was attributed to inclusion of particular calcium source in the diets. The result of this present study indicated that the calcium sources were able to supply the chickens with sufficient calcium enough to maintain bone quality.

The ash content of bones fed different calcium sources is shown in Table 5. There were no significant differences among the treatment means with respect to bone ash of birds on Diet 2 and 3 except for bone humerus. However, significant variations $(p<0.05)$ occurred between bone ash of birds on Diet 1 and the other two Diets. The similar mineral contents observed in birds on Diets 2 and 3 as against Diet 1 might be an indication that the dietary calcium sources were able to adequately supply the birds with the needed mineral combination for egg production.

Table 5: Bone ash (\%) of laying birds fed different calcium sources

\begin{tabular}{lllll}
\hline Parameters & \multicolumn{1}{c}{ Diet 1 } & Diet 2 & Diet 3 & SEM \\
\hline Tibia & $49.50^{\mathrm{b}}$ & $53.67^{\mathrm{a}}$ & $52.25^{\mathrm{a}}$ & 0.24 \\
Femur & $48.83^{\mathrm{b}}$ & $52.34^{\mathrm{a}}$ & $50.25^{\mathrm{a}}$ & 0.32 \\
Humerus & $52.58^{\mathrm{b}}$ & $48.25^{\mathrm{c}}$ & $54.08^{\mathrm{a}}$ & 0.30 \\
Radius & $41.45^{\mathrm{b}}$ & $59.68^{\mathrm{a}}$ & $55.27^{\mathrm{a}}$ & 0.40 \\
Ulna & $47.40^{\mathrm{b}}$ & $53.12^{\mathrm{a}}$ & $57.40^{\mathrm{a}}$ & 0.43 \\
Metatarsal & $46.33^{\mathrm{b}}$ & $60.75^{\mathrm{a}}$ & $59.67^{\mathrm{a}}$ & 0.35 \\
\hline
\end{tabular}

${ }^{\mathrm{abc}}$ means with different superscript on the same row differred significantly $(\mathrm{P}<0.05)$

Table 6: Calcium content in bone mineral of laying birds fed different calcium sources

\begin{tabular}{lllll}
\hline Parameters & \multicolumn{1}{c}{ Diet 1 } & Diet 2 & Diet 3 & SEM \\
\hline Tibia & $31.02^{\mathrm{b}}$ & $17.95^{\mathrm{c}}$ & $33.41^{\mathrm{a}}$ & 0.24 \\
Femur & $32.85^{\mathrm{b}}$ & $16.19^{\mathrm{c}}$ & $34.78^{\mathrm{a}}$ & 0.32 \\
Humerus & $26.80^{\mathrm{b}}$ & $17.89 \mathrm{c}$ & $36.46^{\mathrm{a}}$ & 0.30 \\
Radius & $31.27^{\mathrm{b}}$ & $15.40^{\mathrm{c}}$ & $34.71^{\mathrm{a}}$ & 0.40 \\
Ulna & $60.79^{\mathrm{b}}$ & $43.45^{\mathrm{c}}$ & $66.50^{\mathrm{a}}$ & 0.43 \\
Metatarsal & $31.77^{\mathrm{a}}$ & $13.82^{\mathrm{b}}$ & $32.29^{\mathrm{a}}$ & 0.35 \\
\hline
\end{tabular}

${ }^{\mathrm{abc}}$ means with different superscript on the same row differred significantly $(\mathrm{P}<0.05)$

Table 6 presents the calcium content of bones of laying hens fed different sources of calcium. Significant variation occurred among the treatment means, with birds on Diet 3 recording the highest values among all bone parameters investigated while birds on Diet 2 recorded the lowest value of all bones investigated. This result showed that birds on Diet 3 recovered the highest calcium percentage followed by the birds on Diet 1 and then birds on Diet 2. The lowest percentage value of bone calcium of birds on Diet 2 may be due to the fact that the inherent calcium present in oyster shell was not readily available compared to other diets, thus leading to mobilization of calcium from the bones. This result is in agreement with the findings of Annawistedt (2013) who reported that when intestinal calcium absorption during shell formation cannot meet the requirement, calcium in the bone will be mobilized to meet the requirement thereby reducing bone calcium. 
Comparative use of oyster shell and limestone as sources of calcium in the diet of laying chickens

\section{Conclusion}

It can be concluded that feeding limestone as source of calcium in layer's ration did not have any adverse effect on the performance of the birds, and that limestone can be a useful and adequate alternative to oyster shell.

\section{References}

Ahmed, N. M., Abdel Atti, K. A., Elamin, K. M., Dafalla, K. Y., Malik, H. E. E. and Dousa B. M. 2013. Effect of Dietary Calcium Sources on Laying Hens Performance and Egg Quality. J Anim Prod Adv. 3(7): $226-231 \quad$ D O I : 10.5455/japa.20130718034818

Anna, W. 2013. Shell formation and bone strength in laying Hens; effect of age, Daidzein and Exogenous Estrogen. PhD Thesis from Swedish University of Agricultural Science.

Association of Official Analytical Chemists. 1995. Official Methods of Analysis of Official Analytical Chemists. 16th ed. AOAC Int., Arlington, VA.

Fleming, R. H., McCormack, H. A. and Whitehead, C. C. 1998. Bone structure and strength at different ages in laying hens and effects of dietary particulate limestone, vitamin $\mathrm{K}$ and ascorbic acid. $B r$. Poult. Sci. 39: 434-440.

Grizzle, J., Iheanacho, M., Saxton, A. and Broaden, J. 1992. Nutritional and environmental factors involved in egg shell quality of laying hens. Br. Poult. Sci. 33:781-794.

Guinotte, F and Nys,Y.1991. Effects of particle size and origin of calcium sources on eggshell quality and bone mineralization in egg laying hens. Poultry Science,
70:583-592.

Julian, R. J. 2005. Production and growth related disorders and other metabolic diseases of poultry-A review. Vet. J. 169:350-369.

Keshavarz, I. C., Scott, M. L. and Blanchard, J. 1993. The effect of solubility and particle size of calcium sources on shell quality and bone mineralization, J. Appl. Poultry Res., 2:25-267.

Leeson, S. and Summers, J. D. 2005. Commercial Poultry Nutrition 3rd Edition. University Books Guelph, Ontario, Canada.

NRC (National Research Council) 1994. Nutrient Requirements of Poultry. 9th Revised Edition. National Academy Press, Washington, DC, USA. 155p.

Rennie, J. S., Fleming, R. H., M c C o r m a c k, H . A ., McCorquodale, C. C. and Whitehead, C. C. 1997. Studies on effects of nutritional factors on bone structure and osteoporosis in laying hens. Br. Poult. Sci. 38 : 417 $-424$

Roland, D. A. 1986. Eggshell quality IV: Oyster shell versus limestone and the importance of particle size or solubility of calcium source. World's Poult. Sci. J. 42 : 166 171.

Roland, D. A. and Bryant, M. 1999. Optimal shell quality possible without oyster shell. Feedstuffs. 71 : $18-19$.

SAS Institute. 1999. SAS/STAT User's Guide Release 8.0. SAS Institute Inc., Cary, NC.

Saunders-Blades, J. L., MacIsaac, J. L., Korver, D. R. and Anderson, D. M. 2009. The effect of calcium source and particle size on the production performance and bone 
quality of laying hens. Poultry Science 88 (2): 338-353.

Scheideler, E. S. 1998. Egg shell Calcium effects on egg quality and $\mathrm{Ca}$ digestability in first or third cycle laying hens. Applied Poultry Science.7:69-74.

Scott, M. L., Hull, S. J. and Mullenhoff, P. A. 1971. The calcium requirement of laying hens and effects of dietary oyster shells upon eggshell quality. Poult. Sci. 50:1055-1063.
Webster, A. B. 2004. Welfare implications of avian osteoporosis. Poult. Sci. $83: 184-192$.

Whitehead, C. C. and Fleming, R. H. 2000. Osteoporosis in cage layers. Poult. Sci. 79: 1033 - 1041.

Whitehead, C. C. 2004. Overview of bone biology in the egg-laying hen. Poult. Sci. 83: 193 - 199.

Received $3^{\text {rd }}$ December, 2016 Accepted: $4^{\text {th }}$ March, 2017 